\title{
ÚLTIMAS CLAVES DE UNA GRAN OBRA: LA REJA DEL SEPULCRO DEL CARDENAL CISNEROS
}

\author{
POR \\ ROBERTO GONZÁLEZ RAMOS \\ Universidad de Córdoba
}

La reja del sepulcro del Cardenal Cisneros, encargada por la Universidad de Alcalá en 1566 a Nicolás de Vergara "el viejo" y terminada y asentada en su lugar por su hijo y homónimo "el mozo" en 1591, es una obra bastante bien conocida y documentada. Sin embargo, carecíamos para su correcta interpretación del contrato con las condiciones de realización, entre otros documentos. En este artículo se dan a conocer, interpretan y explican esos documentos, junto con otros no menos importantes, como las trazas realizadas para la ejecución de la obra. Estas nuevas fuentes de información nos aportan una nueva visión del proceso de realización de la reja y de los cambios que sufrió a lo largo de tan dilatado período.

Palabras claves: Nicolás de Vergara; Reja del sepulcro de Cisneros; Colegio Mayor de San Ildefonso; Universidad de Alcalá.

The elaborate bronze railing surrounding the tomb of Cardinal Cisneros is a well-known and relatively well-documented work. Commissioned from Nicolás de Vergara "el viejo" (the elder) by the University of Alcalá in 1566, it was completed and installed in the Saint Ildefonso College Chapel by his son Nicolás de Vergara "el mozo" (the younger) in 1591. Nevertheless, until now, information was lacking for the correct interpretation of this work. New documents along with the preparatory drawings presented in this article provide a fresh vision of the creation of the railing and the changes it underwent during this long process.

Key words: Nicolás de Vergara; Cardinal Cisneros; Bronze railing; Tomb; Saint Ildefonso College Chapel; University of Alcalá.

La reja de bronce que ejecutaron Nicolás de Vergara "el viejo" y su hijo y homónimo "el mozo" para rodear el sepulcro del cardenal Cisneros, situado en la capilla mayor de la iglesia de la Universidad de Alcalá, fue una obra de gran alcance y de una calidad extraordinaria. Elías Tormo dijo de ella que era en todo "superior a las cosas de Benvenuto Cellini"1, fue calificada de

1 Tormo y Monzó, E., “Cartillas excursionistas ‘Tormo'. Alcalá de Henares”, Boletín de la Sociedad Española de Excursiones, XXV, 1917, p. 149. 


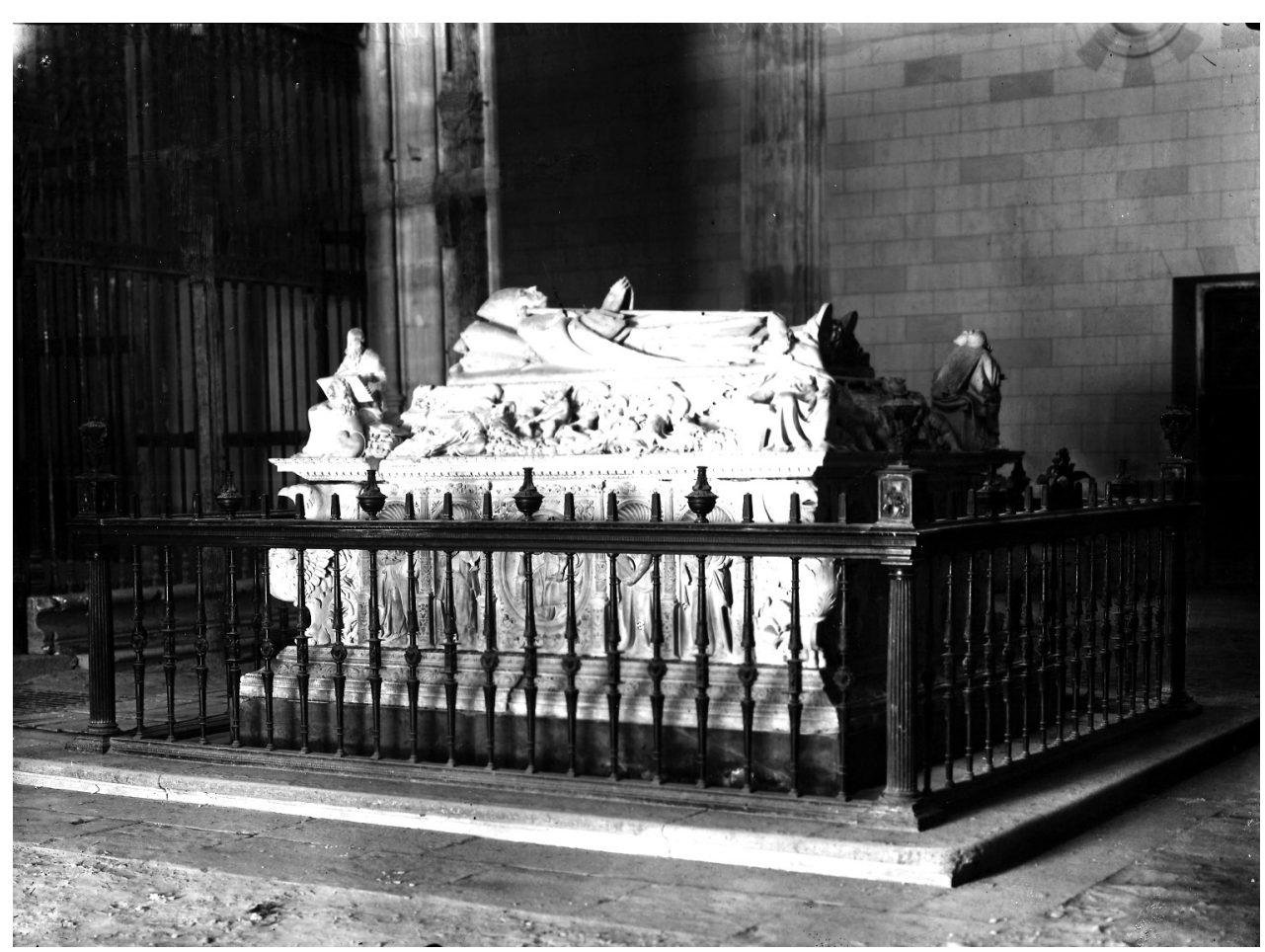

Fig. 1. La reja del sepulcro de Cisneros en la Magistral de Alcalá de Henares, durante su permanencia allí, tras su traslado, en el S. XIX. Archivo Moreno. IPHE, MC.

obra maestra de los broncistas españoles y ha sido valorada como tal ${ }^{2}$. Era una pieza en la que se reunían la rejería, el diseño arquitectónico y la escultura, de un modo muy feliz (fig. 1). Y, como hemos señalado en otra ocasión, se trataba de una creación que formaba parte de un auténtico monumento humanístico a la memoria del Cardenal fundador de la Universidad de Alcalá, junto con la biografía de tan destacado personaje que redactó Álvar Gómez de Castro y que editó la universidad alcalaína en $1569^{3}$.

La reja, a pesar de haber sido destruida en gran parte durante y tras la guerra civil de 1936, ha sido objeto de estudio en diversas ocasiones. Antes, contamos con las citas y menciones de los clásicos de la historiografía artística española ${ }^{4}$, y con un estudio monográfico sobre la obra que le dedicaron en 1929 Terán y Camps (breve y centrado en ilustraciones) ${ }^{5}$. Pero, a pesar

2 Terán, M. y CAmps, E., "La obra maestra de los broncistas españoles: la reja del sepulcro de Cisneros", Archivo Español de Arte y Arqueología, V, 13, 1929, pp. 107-108 y 22 ils.

${ }^{3}$ González Ramos, R., "Arte, arquitectura e historiografía en un monumento humanístico de la Universidad de Alcalá de Henares: la biografía del Cardenal Cisneros y la reja de su sepulcro", Actas del XIV Congreso del Comité Español de Historia del Arte. Correspondencia e Integración de las Artes, Málaga 2002, Málaga, 2003, pp. 191-205.

${ }^{4}$ Ponz, A., Viage de España, Madrid, Viuda de Ibarra, 1787, I, pp. 291-293. CEÁn Bermúdez, J. A., Diccionario histórico de los más ilustres profesores de las Bellas Artes en España, Madrid, Viuda de Ibarra, 1800, V, p. 205. LLAGUNO y Amirola, E., Noticias de los arquitectos y arquitectura en España desde su restauración, Madrid, 1829, III, p. 117. Véase también el famoso artículo de AMADOR DE Los Ríos, J., "Sepulcro del Cardenal Cisneros, custodiado en la Iglesia Magistral de Alcalá de Henares”, Museo Español de Antigüedades, V, 1875, pp. 340-359.

5 TERÁn, M. y CAmps, E., art. cit. 
del artículo de Portela ${ }^{6}$, debemos esperar a que en 1980 Castillo Oreja, en su trabajo sobre el Colegio Mayor de San Ildefonso, diera las claves principales del conocimiento actual sobre la obra broncínea ${ }^{7}$. Algún otro trabajo ha aportado noticias de interés -sobre todo de las últimas vicisitudes y destrucción parcial de la obra $-{ }^{8}$. Estos trabajos han dado una visión muy completa, tanto documental como críticamente, del proceso de la creación de la reja, con sus fechas de encargo, elaboración, conclusión y colocación en la capilla universitaria complutense. Sin embargo, los trabajos más científicamente contrastados, como el de Castillo Oreja, se encontraban con la laguna fundamental, motivada en gran parte por la desaparición de los archivos de protocolos notariales antiguos de Alcalá, de carecer de la referencia valiosísima del contrato inicial, las condiciones de realización y otros detalles, menores pero no por ello menos importantes. Estas carencias impedían, en el caso más extremo, conocer lo que la obra final concluida tenía de cada uno de los dos artífices que se sucedieron en su elaboración, por no hablar de los cambios que se produjeron en el diseño, dado lo dilatado del proceso.

La decisión de encargar la reja fue tomada el 14 de noviembre de 1565 por la capilla plena de rector y colegiales, el órgano de gobierno del Colegio Mayor de San Ildefonso y Universidad de Alcalá, en una sesión en la que se especificaba que el tema se había tratado con anterioridad en diversas ocasiones. Se encomendó al rector, ese año don Alonso de Mendoza, la tarea de ocuparse de todo, cosa que empezó a hacer inmediatamente. El 6 febrero de 1566 se firmó la escritura de contrato entre Nicolás de Vergara "el viejo", maestro de escultura y vidrieras de la catedral de Toledo, y el rector Mendoza, ante el escribano público de Alcalá de Henares Juan Fernández, documento dado por perdido y del que se tenían noticias, entre otras cosas, porque fue refrendado en Toledo en 26 de febrero siguiente. Vergara, como artífice encargado de la reja, comenzó tomando las medidas del sepulcro a rodear y ofreciendo trazas ${ }^{9}$. Después de que pasasen los años sin que se cumplieran los plazos previstos y de que se hubiese prorrogado el contrato, el artífice falleció el 11 de agosto de 1574. Poco después, recogía el testigo de la obra su hijo, Nicolás de Vergara "el mozo"10. El nuevo maestro de la reja procedió a continuar los trabajos, incumpliendo también los plazos, recibiendo prórrogas contractuales, pagos adelantados y abriendo un taller en la propia Alcalá -pues la obra en conjunto se hacía en Toledo- en el que se constata que trabajaron, a las órdenes del aparejador Gregorio de Salazar, varios operarios. Después de transcurrido mucho tiempo, la reja, concluida en todos sus detalles, era montada en torno al sepulcro cisneriano en la capilla mayor de la iglesia universitaria complutense. Corría el mes de junio de 1591. La tasación o tasaciones y los pagos finales por la obra se demoraron

${ }^{6}$ Portela Sandoval, F. J., “Nicolás de Vergara, el mozo”, Goya, 112, 1973, pp. 208-213.

7 Castillo Oreja, M. A., El Colegio Mayor de S. Ildefonso de Alcalá de Henares. Génesis y desarrollo de su construcción. Siglos XV-XVIII, Madrid, 1980, pp. 89-93. Posteriormente pueden verse: Olaguer-Feliú, F. DE, "Rejería arquitectónica madrileña del siglo XVI", Madrid en el Renacimiento, Madrid-Alcalá de Henares, 1986, pp. 268-285. Heredia Moreno, M. C., "Restos de la reja del sepulcro de Cisneros", Una Hora de España. VII Centenario de la Universidad Complutense, Madrid, 1994, pp. 126-127, y "Escudo de la reja del sepulcro de Cisneros", Cisneros y el Siglo de Oro de la Universidad de Alcalá, Alcalá de Henares, 1999, pp. 124-125.

8 Marchamalo, A. y Marchamalo, M., El sepulcro del Cardenal Cisneros, Alcalá de Henares-Madrid, 1985, pp. 61 y ss. Sobre iconografía y posible autoría conceptual: Cordero DE CIRIA, E., "Álvar Gómez de Castro y la introducción en España de la cultura emblemática sin Alciato", Boletín del Museo e Instituto "Camón Aznar", LXXIII, 1998, pp. 59-99.

9 Decimos que la reja iba a rodear el sepulcro, para hacer notar que la explicación dada a su contratación desde un punto de vista exclusivamente utilitario, es decir, para proteger el sepulcro de las agresiones a que había sido sometido, no es razonable. En primer lugar porque semejante obra tiene, manifiestamente, un significado más profundo y, en segundo, porque desde algún tiempo el sepulcro venía estando protegido por una balaustrada de madera. Véase GONZÁLEZ RAMOS, R., art. cit., p. 204.

${ }^{10}$ En su testamento, "el viejo" había traspasado algunas de sus obras en ejecución a su hijo, incluida la fundición de la reja alcalaína. Cfr. MARíAs, F., La arquitectura del Renacimiento en Toledo (1541-1631), Toledo, 1983, I, p. 363. 
un poco más, pues el Colegio Universidad se negó a abonar cantidad alguna y al nombramiento de un tercer perito neutral, que era lo que estaba concertado en las escrituras en el caso de que los tasadores de ambas partes no llegaran a un acuerdo. El artífice, debido a ello, llevó a juicio a la institución académica ante el único tribunal que, por fuero universitario, podía ver el caso, el Consejo Real de Castilla. El pleito no requirió sentencia, pues ambas partes llegaron un acuerdo o concordia, que fue confirmado por el tribunal y por Felipe II el año 1593, después de lo cual se terminó de pagar la obra a Nicolás de Vergara "el mozo".

Ha sido, precisamente, el detallado informe económico de gastos que acompaña a la concordia citada, el puntal documental sobre el que reconstruir todo el proceso de elaboración de la reja. Una serie de datos contables bastante correcta va señalando las fechas de los distintos pagos y traspasos de responsabilidad al frente de la obra. Todo este cúmulo de información fue sacado, como es lógico, de los libros y demás registros contables llevados por los notarios contadores del Colegio y Universidad de Alcalá. Un repaso de esas fuentes documentales nos da confirmación, e incluso matiza, lo ya sabido. Otras fuentes de información han sido las actas de las capillas plenas del Colegio mayor de San Ildefonso, donde se pueden encontrar las discusiones de los colegiales sobre el asunto de la reja, las tomas de decisiones y otros detalles referidos a la obra en cuestión. Se conocían algunas relevantes (como la de la toma de decisión de su encargo) pero, como es lógico, no todas las que aportan datos importantes. Finalmente, un gran número de documentos notariales, algunos conservados entre los llevados por los notarios de la Universidad, otros localizados en Toledo y otros lugares, aportan datos sobre contratos, prórrogas de contratos y poderes, entre los que destaca la escritura otorgada por Vergara "el mozo" para relevar a su padre al frente de la obra de la reja del sepulcro de Cisneros ${ }^{11}$.

El pleito entablado entre Nicolás de Vergara "el mozo" y el Colegio Mayor de San Ildefonso y Universidad de Alcalá ante el Consejo Real, motivó que se solicitasen a los distintos escribanos copias de los documentos relativos a la obra de la reja. Aunque se sabía que dicho pleito había tenido lugar, hasta ahora no se había localizado el corpus documental que generó. Nosotros podemos darlo a conocer ahora y, con él, todos los documentos que nos faltaban para reconstruir las lagunas sobre la obra y su proceso de realización. Entre estas fuentes documentales tenemos, en primer lugar, el contrato que firmaron el rector Mendoza y Vergara "el viejo", incluyendo las condiciones que debían seguirse en la realización de la obra. Estas condiciones, como es habitual, nos informan de multitud de detalles técnicos, formales e iconográficos. Lo mismo -en distinto grado- nos ofrece un documento que no fue copiado, dado su carácter, sino remitido al Consejo original: la traza que el artífice adjuntó al contrato y a las condiciones. Todo ello nos señala cómo fue el primer proyecto, su forma, su mensaje y su significado originarios.

A continuación, entre los referidos a otras muchas cuestiones, tenemos los documentos relativos a la transformación del proyecto original llevado a cabo por el segundo de los artífices encargados de la reja, Vergara "el mozo", incluyéndose entre ellos la traza que presentó como referente visual de la nueva forma propuesta para la obra, traza que, como en el caso anterior, es un original sacado de su antiguo archivo para entregarse al alto tribunal, dada la imposibilidad de realizar una copia jurídicamente válida. A continuación, contamos con las tasaciones realizadas por los peritos nombrados por cada una de las partes, según especificaba el primer contrato. Éstas, además de cuestiones de detalle que aluden, por ejemplo, a pesos, precios, calidades, etc., se refieren a la reja tal cual se concluyó, señalando y explicando -a veces justificando- los cambios

${ }^{11}$ Para un completo repaso del corpus documental existente en el antiguo archivo universitario alcalaíno (AHN, Universidades) referido a la reja del sepulcro del Cardenal Cisneros, previo a la localización de los documentos que aportamos en este artículo, puede verse GonZÁlez RAMOs, R., El mecenazgo artístico de la Universidad de Alcalá de Henares (siglos XVI-XIX): inventario crítico de su patrimonio pictórico y escultórico (Tesis Doctoral) Universidad Autónoma de Madrid, 2004, pp. 230-252. 
que se habían introducido con respecto a lo señalado en la segunda traza aludida. Finalmente, las alegaciones de los procuradores ante el tribunal nos ayudan a comprender las razones de una y otra parte, así como las circunstancias en las que se desarrolló el pleito hasta su conclusión.

\section{Primera escritura, condiciones y traza}

El grueso de los documentos del pleito que, ante el Consejo Real de Castilla, se siguió entre Nicolás de Vergara "el mozo" (denunciante) y el Colegio Mayor de San Ildefonso y Universidad de Alcalá (denunciado), se conserva hoy día en el Archivo Histórico Nacional de Madrid, sección Consejos, legajo 28281 (Escribanía de Pinilla, n. ${ }^{\circ}$ 1, folio 1 y siguientes). Como hemos señalado, entre los numerosos papeles de interés que conserva ese legajo, incluidos órdenes del Consejo, sus determinaciones, poderes, documentos notariales compulsados y demás, encontramos la copia autentificada del contrato y las condiciones que se firmaron, como veíamos, en Alcalá de Henares, ante el escribano público Juan Fernández, el 6 de febrero de $1566^{12}$.

Las condiciones que ambas partes concertaron para la realización de la reja comienzan indicando las medidas generales de la obra, y la forma y medidas de la "suela de mármol" sobre la que iba a asentarse. Dicha "suela" debía mostrar en sus frentes "rrebajado un tablero y a trechos unos aobados donde se embebe con unos espejos de jaspe". A continuación se comienza a tratar la obra de bronce, la reja propiamente dicha, y se comienza, como es lógico, por abajo, por el "embasamento". Este "embasamento", con sus medidas, debía llevar las molduras y ornamento que "convenga al género de que se haze la dicha rreja, el qual ha de ser Dórico". Sobre el referido "embasamento" iban a disponerse una serie de balaústres y unas cariátides, cuyas molduras, basas y capiteles debían asimismo ajustarse al género dórico. Enseguida encontraremos referencias más claras sobre la sorprendente aparición de las citadas cariátides, pero por el momento debemos detenernos a señalar la corrección del uso del decoro vitruviano al elegir para rodear la sepultura de un recio hombre de iglesia y estadista, el orden arquitectónico clásico que mejor se ajustaba a su carácter, el adusto dórico.

Inmediatamente después, las condiciones pasan a referirse a la forma y las medidas de la cornisa de la estructura, con su decoración apropiada, molduras, hojas, festones, flores u otras. La siguiente partida se refiere a los balaústres a situar entre basamento y cornisa. Debían seguir dos modelos y sumar, en total, sesenta y ocho en los cuatro paños de la reja, dejándose la especificación de sus dos variantes a lo detallado en la traza, que luego veremos. Seguidamente, otra partida se detiene en las "figuras y pedestales y historias dellos con su ornamento". Cuatro cariátides habían de servir de pilares en las cuatro esquinas de la reja. Cada una de estas figuras debía situarse encima de sus respectivos "dados quadrados", que más que cubos habían de ser paralelepípedos, especificándose que debían ser de proporción sesquiáltera, alargados en vertical. Señala el pliego de condiciones que en cada una de las caras o facetas libres de estos pedestales o "dados", debían labrarse "unos rebaxos" dentro de los cuales, de medio relieve, se situarían "las ystorias de la victoria de Orán con las demás que el señor don Alonsso rector de dicho colegio diere por memoria". En las esquinas de dichos paralelepípedos historiados, "al pie de ellos", debían situarse cuatro figuras de cisnes a manera de ornamento, decoración que debía verse completada por festones, que colgarían de caretas dispuestas en la parte superior de dichas esquinas o cantos.

Como podemos ver, en contraste con su situación final en la reja concluida, los elementos portadores de la mayoría del mensaje iconográfico de la reja, los pequeños pedestales historiados, iban a situarse en origen en las esquinas de la obra, bajo las figuras de las aludidas cariátides, ac-

${ }^{12}$ AHN, Consejos, Legajo 28281, Escribanía de Pinilla, n. ${ }^{\circ}$, folio 4 r. ${ }^{\circ}-7$ v. ${ }^{\circ}$ Copia en poder de Vergara. Hay versión en el mismo legajo, copia realizada con motivo de las actuaciones del pleito. 
tuando de pedestales. El rector Mendoza se iba a encargar de proporcionar al artífice las "historias" o motivos a disponer en las caras o facetas de esos pedestales, estando previsto que uno de ellos representase la batalla victoriosa de Orán. El resto, más que el rector -quien proporcionaría la "memoria" en tanto que comisionado por los colegiales-, los definiría alguna persona que, a manera de iconógrafo, desarrollase todo el programa referido a la vida y hechos del Cardenal Cisneros. Sin querer desviarnos aquí de nuestro propósito principal, debemos señalar que la persona más indicada en aquel momento era el humanista y antiguo universitario complutense Álvar Gómez de Castro, autor de la documentada biografía latina del fundador del Colegio Universidad ${ }^{13}$. Por otro lado, es de señalar la profusa decoración que completaría las esquinas de los pedestales historiados, con referencias heráldicas (los cisnes) y motivos decorativos de tipo renaciente-manierista.

Sobre esos elementos narrativos y decorados, como continúa señalando el pliego de condiciones, se iban a asentar las cuatro figuras de cariátides. Estas figuras debían llevar su capitel dórico sobre la cabeza e irían vestidas "del hábito africano", representando prisioneros de ese origen -nueva referencia a la batalla y conquista de Orán-. Además de a esos prisioneros, las figuras representarían "los biçios que ofenden al estudio de las letras", portando las "ynsinias y afectos que convengan a los dichos viçios". Es decir, que las cariátides no eran un mero recurso compositivo-decorativo, sino que portaban gran parte del mensaje iconográfico global de la obra. La referencia a la mesiánica campaña cisneriana de la toma de Orán se mezcla con alusiones a los estudios universitarios utilizando el recurso de la figura del prisionero, que representa a los vicios o enemigos vencidos por el personaje a cuyo sepulcro se asocian. En este caso, debido a que la obra estaba destinada a la fundación cultural más importante del Cardenal Cisneros, los vicios vencidos no eran comunes, sino los que iban en contra de los estudios universitarios. No podemos evitar en este punto hacer alusión al sepulcro de Julio II de Miguel Ángel y a sus famosos cautivos, que también representaban los vicios vencidos por el sepultado. Aunque el recurso iconográfico alegórico pudo haberse tomado de otra fuente, no debemos olvidar que el propuesto iconógrafo y autor de la faceta literaria del monumento humanístico del que la reja del sepulcro cisneriano formaba parte, Álvar Gómez de Castro, poseyó y anotó un ejemplar de las famosas Vite de Giorgio Vasari en las que se hace alusión al sepulcro del Papa Della Rovere y al significado de los cautivos miguelangelescos ${ }^{14}$.

Inmediatamente después, las condiciones se refieren a las figuras de cuatro virtudes que debían situarse, sobre la cornisa, a plomo encima de las figuras de los prisioneros. Se trataba de cada una de las virtudes que se oponían a los viçios representados por las cariátides, por lo que, aunque no se especifiquen cuáles eran, debían referirse a los estudios de las letras ${ }^{15}$. La situación

\footnotetext{
13 Cordero de Ciria, E., Art. cit., pp. 88-89.

14 Primera edición de 1550. Véase Bustamante García, A., "Vasari y Álvar Gómez de Castro", Boletín del Museo e Instituto “Camón Aznar”, XXXVII, 1989, pp. 51-86.

${ }_{15}$ Representaciones de las virtudes necesarias para el estudio de las letras o "cosas que son necesarias y valen mucho para las letras" encontramos en muchos de los aparatos efímeros levantados por la Universidad de Alcalá en acontecimientos importantes, como visitas reales. En 1560, con motivo de la visita a la Universidad de Felipe II e Isabel de Valois, se colocaron cuatro grandes figuras "arrimadas a las columnas" de uno de los arcos triunfales efímeros levantados entonces. Representaban al Ingenio, la Doctrina, el Ejercicio y la Perseverancia. En 1580, ante la prevista visita de Felipe II y su sobrino el Cardenal Alberto de Austria, otro arco iba a mostrar las figuras del Ingenio, la Prudencia, la Perseverancia y el Trabajo. Sobre el primer acontecimiento y las decoraciones véase: El recebimieto, que la Vniuersidad de Alcala de Henares hizo a los Reyes nuestros señores, quando vinieron de Guadalajara tres dias despues de su felicissimo casamiento, Alcalá de Henares, Juan de Brocar, 1560, fols. C1 v. ${ }^{\circ}-\mathrm{C} 2$ r. ${ }^{\circ}$ Alvar EzQuerRA, A., "Los recibimientos que Alcalá de Henares y Madrid tributaron a Isabel de Valois tras su boda con Felipe II", I Jornadas de estudios sobre la provincia de Madrid, Madrid, 1979, pp. 693-700. AlastruÉ CAMPO, I., Alcalá de Henares y sus fiestas públicas (1503-1675), Alcalá de Henares, 1990, pp. 95 y ss., entre otros títulos. Sobre el acontecimiento de 1580, véase GonZÁlez RAmos, R., "La visita del archiduque cardenal Alberto de Austria a la Universidad de Alcalá de Henares y la obra efímero-emblemática del pintor Juan de Cerecedo", Boletín del Museo e Instituto "Camón Aznar", XC, 2003, pp. 77-98.
} 
de las virtudes sobre los vicios quería significar, obviamente, que triunfaban sobre ellos -gracias a Cisneros, debemos añadir-. También sobre la cornisa, se debían distribuir otros elementos menores. Se trataba, siguiendo el documento de las condiciones, de diez vasos que iban a hacer la función de hacheros, con sus recipientes para recoger la cera derretida, pues servirían para poner en ellos las hachas de las solemnidades de las honras anuales por el alma del cardenal y otras festividades del Colegio Universidad. Seguirían dos modelos, debiendo ser unos mayores que otros y tener diversa distribución. Además de esos vasos, estaba previsto que se colocasen sobre la cornisa dos "compartimentos", uno de las armas de Cisneros con su capelo flanqueadas por cisnes tenantes situado en uno de los testeros, y otro -en el otro testero- con un óvalo en el que debía rotularse "la declaración de toda la dicha reja". Más adelante, se hace referencia a que sobre la cornisa irían unos obeliscos, entre los vasos antes referidos, con una punta afilada en la que poner cirios o candelas.

Las condiciones también hacen alusión a ciertos detalles menores, como que la reja tendría puertas para que se pudiese acceder al sepulcro de mármol y así poder limpiarlo, y que junto a dicha puerta se colocarían unas arandelas en cornisa y basamento para introducir el asta del guión del Cardenal, que se ponía junto al sepulcro en ocasiones especiales. Los materiales, finalmente, se especifican en una penúltima condición, señalándose que el material debía ser bronce con refuerzos y guarniciones internos de hierro para "hazer fuerte toda la dha obra". La última condición exigía que la obra se realizase conforme a la traza que Nicolás de Vergara "el viejo" había entregado, pero si éste veía necesario cambiar algo en el proceso de ejecución de la reja, no se le pondría ningún impedimento siempre que lo comunicase y recabase la autorización del rector.

La traza que aparece entre los papeles del pleito (fig. 2) es un documento de gran valía ${ }^{16}$. Como veíamos, no se trata, como en el caso de los documentos, de una copia, sino la traza ori-

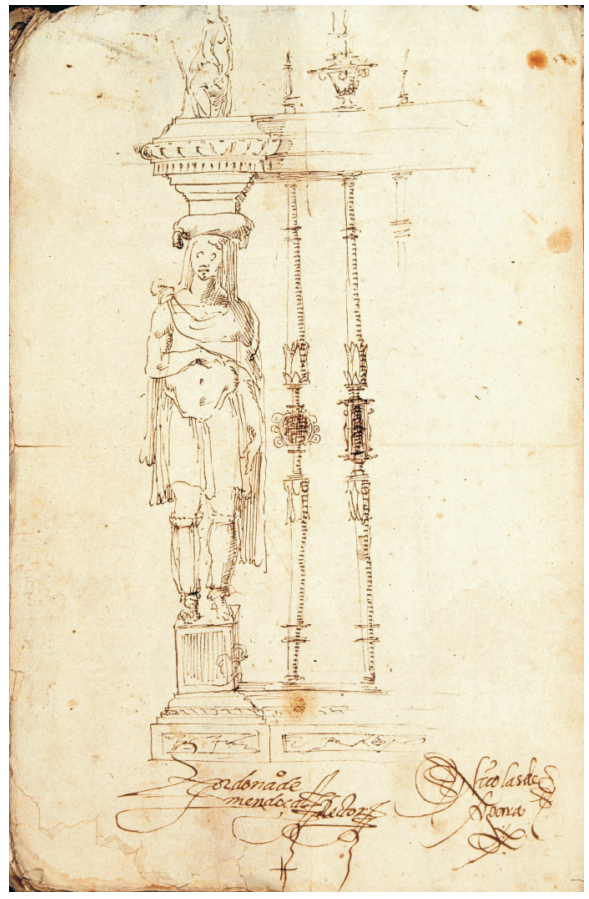

Fig. 2. Nicolás de Vergara "el viejo". Primera traza para la reja del sepulcro de Cisneros. 1566. Archivo Histórico Nacional. Sección Consejos. Legajo 28281.

${ }^{16}$ AHN, Consejos, Legajo 28281, Escribanía de Pinilla, n. ${ }^{\circ}$ 1, folio 36 v. ${ }^{\circ}$ 
ginal que hizo Vergara el "viejo" para acompañar a la escritura de obligación. Está dibujada a pluma sobre un folio corriente de papel $(21,4 \times 31,6 \mathrm{~cm})$ y de una forma poco cuidadosa, siendo más un apunte, boceto o "rasguño", indicador somero de lo que se planteaba hacer, que otra cosa. De hecho, como veremos enseguida, únicamente muestra un ángulo de uno de los lados mayores del monumento, no un alzado arquitectónico con su planta y pitipié. El dibujo va rubricado por Nicolás de Vergara y por el rector don Alonso de Mendoza.

En primer lugar, abajo, el diseño tiene representada la "suela" de mármol y jaspe con su cajeado, uno de los espejos, de formato romboidal, y una maraña de líneas que representan seguramente las vetas de la piedra. Encima de la "suela", apreciamos el molduraje del basamento de bronce y, sobre él, dos balaústres y una de las cariátides de los ángulos, elevada sobre uno de los pedestales de proporción sesquiáltera. Lógicamente, cada uno de los balaústres muestra uno de los dos modelos señalados en las condiciones, que únicamente se diferencian en que en el centro portan o un medallón rodeado de lóbulos, o un elemento paralelepípedo con figurillas humanas en altorrelieve en cada una de sus facetas largas. Se trata de piezas de proporciones muy estilizadas, más parecidas a los barrotes de la rejería arquitectónica que a los balaústres propiamente dichos. El pedestal de la figura del prisionero no muestra más que su forma aproximada, con el cuadro para la correspondiente escena y una especie de cisne en uno de los cantos. La cariátide, dibujada en ligero "contrapposto", va ataviada, más que con "hábito africano", con vestimenta militar romana antigua, con coraza y faldellín, portando una larga clámide anudada sobre el hombro izquierdo, y una especie de grebas o polainas. Sobre la cabeza encontramos una almohada en la que se apoya el capitel de pilar dórico que señalan las condiciones. Se trata de una figura de aspecto muy clásico, pese a lo breve, somero, del dibujo. La cornisa aparece también dibujada de una forma muy sencilla, únicamente insinuando el molduraje y el adelantamiento producido a plomo con la cariátide. Una serie de lengüetas o dentículos, un filete y un cimacio anteceden a otras molduras que, en disminución, pertenecen ya a la parte superior. Arriba tenemos representada, también de forma muy sumaria, una figura sentada con un atributo en las manos y, a plomo sobre los barrotes-balaústres, unos inidentificables obeliscos o pirámides afilados, y un vaso. No aparecen la cartela ni el escudo.

Todos estos elementos, aunque por sus intereses y formación pudieran haber sido tomados por Vergara "el viejo" de modelos, dibujos y otros referentes visuales -incluidos los que aparecen en los tratados-, tienen claros antecedentes en las rejas que, sin ir más lejos, se habían venido diseñando y realizando en la catedral de Toledo. No faltaban en la Ciudad Imperial ni en la Primada ejemplos de figuras humanas que, como cariátides, atlantes, telamones o términos, completaban las estructuras de obras como las rejas de la capilla mayor ${ }^{17}$. Otras obras de Francisco de Villalpando, como la portada del Colegio de Infantes toledano también presentan figuras de cariátides-hermas, dentro de este repertorio tan amplio de motivos que Müller Profumo denominó "el ornamento icónico de la arquitectura"18. Desde luego, tanto Villalpando como los hermanos

${ }^{17}$ Pueden verse: Llaguno, E., Ob. cit., II, pp. 220 y ss; Ramírez DE Arellano, R., Estudio sobre la Historia de la Orfebrería Toledana, Toledo, 1915. Zarco Del VAlle, M. R., Datos documentales para la historia del arte español. II. Documentos de la Catedral de Toledo, Madrid, 1916, I, pp. 304 y ss. Rivera ReCio, F., "El Cardenal Tavera y los maestros de rejas de la Catedral toledana, Céspedes y Villalpando", Boletín de la Real Academia de Bellas Artes y Ciencias Históricas de Toledo, XXV, 1947, pp. 1-14. CAMÓn AZNAR, J., La escultura y la rejería españolas del siglo XVI, Madrid, 1961, pp. 433-440. Olaguer-Feliú, F. DE: Las rejas de la Catedral de Toledo, Toledo, 1980. Marías, F., Ob. cit., I, pp. 303 y ss.

18 MÜller Profumo, L., El ornamento icónico y la arquitectura, 1400-1600, Madrid, 1985. Véase, sobre las figuras aplicadas a la arquitectura y rejería, al hablar de Francisco de Villalpando: MARÍAS, F., Ob. cit., I, p. 317-320. Sobre el Colegio de Infantes y otras obras, véanse, entre otras publicaciones: MARÍAs, F., "Los artistas del Colegio de Infantes en Toledo”, A.E.A., XLIX, 1976, pp. 92-95. Díez del Corral, R.; NAVAscú́s, P. y SuÁrez, D., Arquitecturas de Toledo, Toledo, 1991, II, pp. 45 y ss. 
Corral demuestran en sus obras la gran riqueza y las enormes posibilidades que ese repertorio ofrecía al diseñador de elementos decorativo-arquitectónicos. Pero es especialmente importante destacar que la propuesta de Vergara "el viejo" para el Colegio de Alcalá está más conectada con dicha especialidad rejera desarrollada tan magníficamente por Villalpando y el maestro Domingo de Céspedes, que con obras de arquitectura o escultura propiamente dichas. No sólo las grandes figuras de los ángulos, sino también y especialmente los balaústres-barrotes y los elementos horizontales muestran esta conexión directa. De hecho, el modelo de medallón que muestra uno de los dos tipos de balaústres diseñados para Alcalá (y, por supuesto, el resto del perfil de la pieza lo encontramos en otros muchos ejemplos de la Primada), aparece en una obra no muy posterior, la reja de la capilla del enterramiento de don Alfonso de Rojas de la catedral de Toledo ${ }^{19}$. La escritura de obligación finaliza especificando los plazos de ejecución y entrega, condiciones de pago y demás detalles, ya conocidos gracias al documento de confirmación de la escritura antes citado (26 de febrero de 1566$)^{20}$.

\section{El cambio de proyecto y su traza}

El relevo en la dirección de los trabajos de la reja del sepulcro cisneriano recayó, tras el deceso del primer maestro, en Nicolás de Vergara "el mozo", como hemos tenido ocasión de apuntar. Vergara "el mozo" firmó su escritura de obligación, aceptando las condiciones firmadas por su padre, en Toledo el 28 de septiembre de 1574. El Colegio se comprometía a abonarle 1.000 ducados en seis plazos, a uno cada trimestre, y el artífice a acabar la obra en año y medio ${ }^{21}$. El Colegio pagó la última cantidad o plazo en enero de 1578, incumpliendo lo acordado. Vergara "el mozo" tampoco cumplió, como tampoco cumpliría con las sucesivas prórrogas del contrato hasta que, como vimos, la obra se instalara en su lugar en junio de $1591^{22}$.

Pero antes, el artífice iba a proponer un cambio sustancial en el diseño de la obra. En una de sus múltiples solicitudes a la capilla colegial de San Ildefonso, concretamente en una petición presentada en la sesión del 17 de febrero de 1583, Vergara "el mozo" planteaba diversas cuestiones o "apuntamientos". Dos de ellas se referían a que se le entregase cierta cantidad de dinero para la conclusión de los trabajos, y que se pagasen los jornales a los operarios que tenía en el taller montado en la propia Alcalá para la obra de la reja. La tercera de esas peticiones es la que ahora nos interesa. Vergara "el mozo" alegaba que, en su opinión, "lleva alguna superfluidad la reja", por lo que se ofrecía a dar dos trazas para "que se çercene alguna cosa", solicitando que dos de los colegiales "resuman lo que más cumpliere y sea mejor". Nos encontramos ante una más que probable intención de simplificar el diseño para ahorrar materiales y trabajo -los costes por ambos conceptos a la postre serían la principal causa de todos los problemas en relación con la reja-, junto con la necesidad de adecuar el estilo del monumento a uno más actualizado y moderno, teniendo en cuenta que habían pasado casi veinte años desde que se realizara el diseño originario y que en la Castilla central los gustos habían evolucionado bastante. Lo cierto es que la capilla colegial decidió, en este asunto, nombrar a dos colegiales para que viesen las trazas que ofrecía Vergara "y traten lo que mejor estubiere y paresçiere y den aviso dello en la capilla"23. Pasados nueve meses, la capilla (5 de noviembre) decidía que "el orden que se da de nuebo en la reformaçión de la reja" se consultase con algunos colegiales antiguos "para que se vea lo que

\footnotetext{
19 Sobre esta última reja, véase: Olaguer-Feliú, F. DE, Ob. cit., pp. 210-211.

${ }^{20}$ Castillo Oreja, M. A., Ob. cit., documento 19, pp. 138-140.

${ }^{21}$ Ob. cit., documento 20, pp. 140-142.

22 Ob. cit., pp. 145-146.

23 AHN, Universidades, libro 1112, folio 195 v. ${ }^{\circ}$
} 
más cumple" 24 . Parece que quería contarse con la opinión de personas que tuviesen mayor grado de conocimiento sobre las intenciones primigenias de la obra, para que se pudiese tomar una decisión sin traicionar el concepto y el significado originales del proyecto. No sabemos cuántas trazas nuevas entregó Vergara "el mozo" a los colegiales. Lo que sí podemos constatar es que una de ellas pasó por las manos de un colegial, el doctor Segura, quien "cumpliendo lo decretado en capilla y por el $\mathrm{S}^{\mathrm{r}}$. Rector [h] a visto esta traça de la reja y la que se hiço primero y entendido el $\mathrm{a}[\mathrm{h}]$ orro desta y el fin de la una y de la otra le pareçe esta muy propia y conbiniente ques la de estotraparte y que se guarde y haga así lo que falta por haçer della", firmando esta declaración el 7 de noviembre, junto con las rúbricas de otros cinco colegiales y del secretario de la capilla ${ }^{25}$.

Esta especie de breve informe consta en el vuelto de las trazas que se aprobaron finalmente como referente visual para la conclusión del proyecto. Se conservan al lado del dibujo que había presentado Vergara "el viejo" en 1566. Se retiró del registro de escrituras del escribano del Colegio Universidad para entregarse, como documento probatorio, en el pleito llevado ante el Consejo Real. Esta vez no se trata de un dibujo más o menos orientativo plasmado a mano alzada (fig. 3). Es toda una traza de carácter arquitectónico que muestra la planta y el alzado de uno de los frontales de la reja del sepulcro cisneriano, con plasmación muy precisa y detallada, en sus 40,5 × 25,5 cm de tamaño. Está firmada por Nicolás de Vergara "el mozo" y por el rector de turno, el doctor Francisco Martínez. Como podíamos suponer, en el dibujo han cambiado muchas cosas si lo comparamos con el anterior y lo que exigían las condiciones. Han desaparecido muchas cosas "superfluas" y, como sospechábamos, se ha modernizado estilísti-

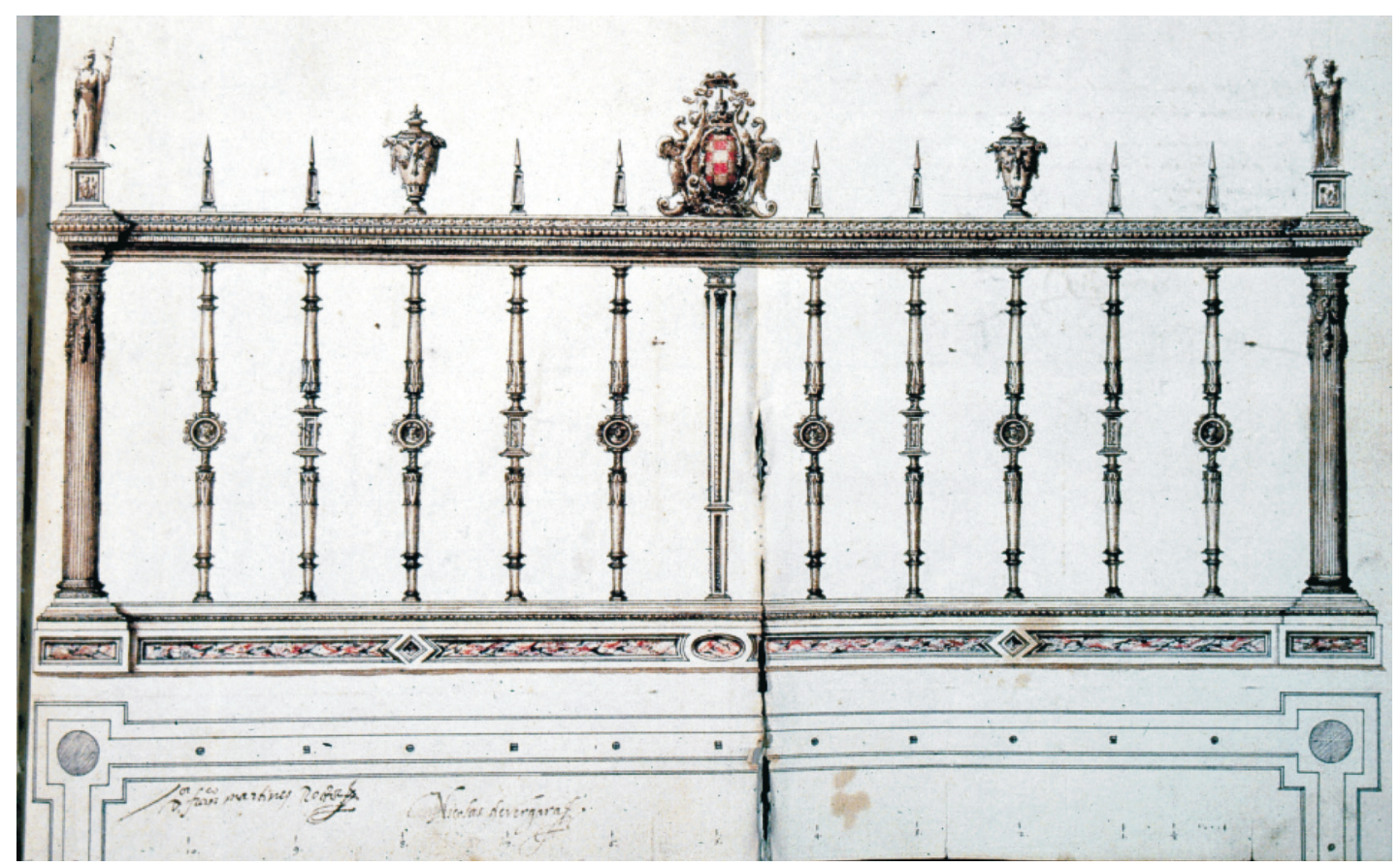

Fig. 3. Nicolás de Vergara "el mozo". Segunda traza para la reja del sepulcro de Cisneros. 1583. Archivo Histórico Nacional. Sección Consejos. Legajo 28281.

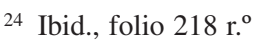

25 AHN, Consejos, legajo 28281, folio 37 v. ${ }^{\circ}$
} 
camente eliminando figuraciones y decoraciones, que son sustituidas por elementos de mayor sobriedad y clasicismo. Abajo encontramos representada la "suela" de mármol y jaspe, con su veteado, cajeado con losanges y espejo elíptico. De la obra de bronce, tenemos el basamento y los balaústres, que siguen en todo los dos formatos que había definido Vergara "el viejo", pero en las esquinas no encontramos ya las cariátides sobre los plintos historiados y decorados, sino columnas que, siguiendo lo especificado en las condiciones primeras en lo referido al orden arquitectónico, son dóricas. Se trata de un dórico a la romana bastante elaborado, con basa figurando corona de laurel, con unos festones colgantes del capitel, sobre la parte superior del fuste, y con los propios capiteles con rosetas en el collarino -muy a la vignolesca- y equino decorado con ovas y flechas. Aunque la desaparición de las cariátides suponía la eliminación de parte del mensaje iconográfico de la reja, los pequeños pedestales que las elevaban no han desaparecido aquí. Se han trasladado en el dibujo - mantendrán esa posición en la obra acabada- a la parte superior, sobre los ángulos de la cornisa, a plomo con las columnas. Es una posición mucho más cómoda de lectura de su programa de relieves que la que se le había asignado anteriormente. Han perdido, además, todo el cúmulo decorativo de cisnes, caretas y guirnaldas que debían llevar en sus ángulos. Tampoco han desaparecido las figuras de las virtudes que tenían asignado el nuevo lugar de los pequeños pedestales decorados, pues éstas han pasado a coronar los bloques paralelepípedos. Las virtudes están representadas en pie, someramente dibujadas, levantando cada una su atributo.

Encima de la cornisa, en el tramo abalaustrado, podemos ver las copas y los obeliscos con las puntas afiladas. Las copas no se parecen en nada a las previstas en el primer diseño, pues son verdaderas urnas al modo funerario antiguo. Están recubiertas de decoración consistente en caretas, festones, cisnes exployados y otros motivos. Son diseño, pues, de Vergara "el mozo" y permanecerán en la obra definitiva, pero en otro lugar. En el centro del tramo podemos ver un escudo de las armas de Cisneros ovalado, sostenido por cisnes tenantes y con capelo portado por niños desnudos que se descuelgan por la cartela del símbolo heráldico. También aparecerán de esta forma en la reja terminada y en el mismo lugar, siendo de la misma forma que las urnas, creación de Vergara "el mozo". La cornisa se parece enormemente a la diseñada por Vergara "el viejo", habiéndosele añadido únicamente, abajo, un breve entablamento. Finalmente, nos queda por ver un elemento extraño, dada su forma y colocación. Es un estípite con capitel dórico y decoración abstracta, situado entre los balaústres y marcando el eje central del frontal aquí representado. Con esta nueva disposición, no sólo se abreviaban las líneas del monumento, actualizando su estilo, o se ahorraba en materiales, sino que simplificaba también el mensaje, eliminando las referencias a la conquista de Orán personificada en los prisioneros africanos, y a los vicios enemigos del estudio de las letras, que tan estrechamente ponían en conexión la figura del Cardenal Cisneros con su ilustre fundación universitaria, que acogía su sepulcro. No se debió ver en esta simplificación un atentado contra el espíritu del monumento -recordemos que las virtudes se mantienen-, que conservaría lo esencial.

\section{La reja terminada y las tasaciones}

Después de que la reja fuera concluida y colocada en torno al sepulcro cisneriano en la capilla mayor de la iglesia del Colegio Mayor y Universidad de Alcalá, en junio de 1591, se procedió a tasarla, no sin ciertas dificultades puestas por los colegiales, que abajo veremos. Para ello, el 15 de junio de ese año se procedió a la toma de juramento de los tasadores nombrados por ambas partes $^{26}$. Por parte de los universitarios había sido nombrado el alcalaíno Miguel Ruiz, platero

${ }^{26}$ Juramento, tasaciones y otros documentos relacionados con ellas, en: Ibid., folios 41 r. $^{\text {o }}-46$ v. ${ }^{\circ}$ 


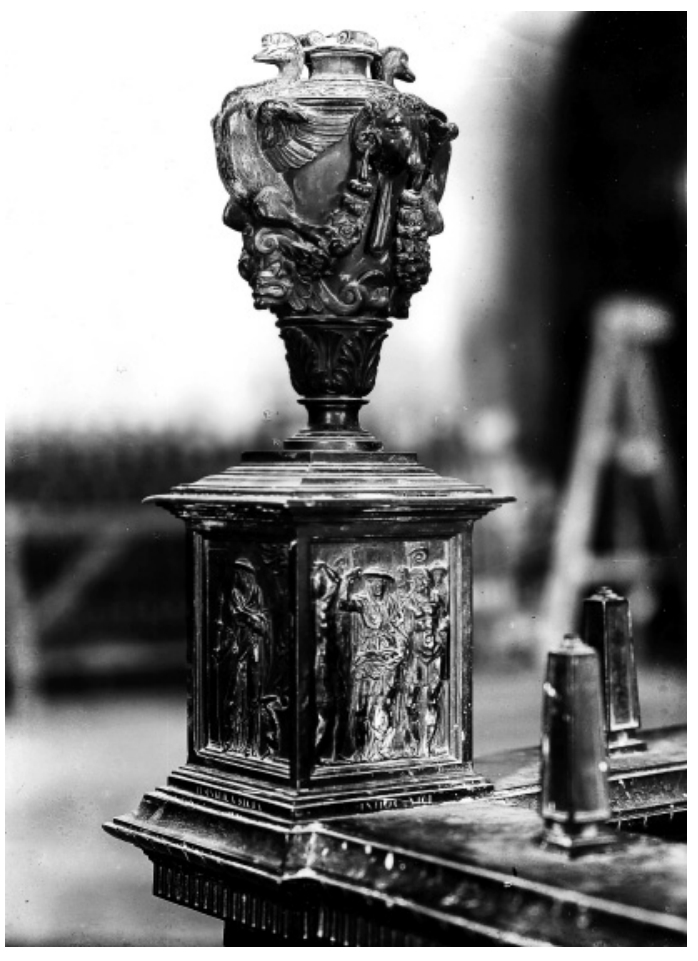

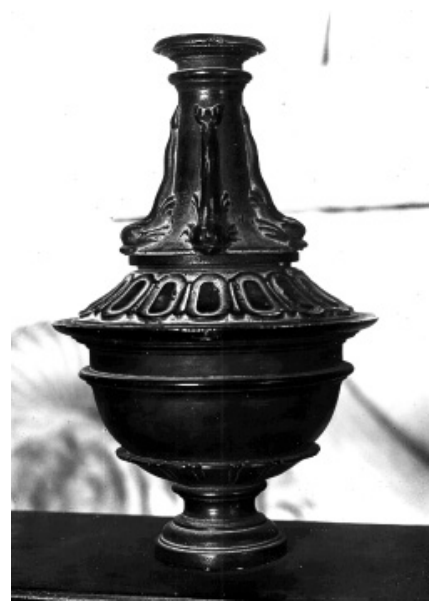

Fig. 5. Copa. Reja del sepulcro del Cardenal Cisneros. Archivo Moreno. IPHE, MC.

Fig. 4. Pedestal angular con su urna.

Reja del sepulcro del Cardenal Cisneros. Archivo Moreno. IPHE, MC.

del Colegio. Por la parte de Vergara "el mozo" actuaría Francisco Merino, maestro platero de la catedral de Toledo. El tasador de Vergara realizó una primera valoración sin entrar en detalles por menor. En ella señalaba que todo se había hecho conforme a las trazas y escrituras, "y esto con grandes ventajas que se entiende en el quitar los términos e figuras que están en la traça primera y convertirlos en columnas y en las dhas columnas les hiço mejor beneficio en quitarlos la talla que tiene la traça en el deguello de la columna por la p.te de arriba". También consideraba positivo que hubiera colocado los pedestales historiados sobre las columnas "respecto de tener más espacio e dispusiçión" y "muy conbiniente a las historias y letras que contiene en los planos de las dhas pedestales". También veía con buenos ojos la eliminación en la obra concluida de "las figuras que están en la traza // en los ángulos encima de los pedestales y poner los basos que agora están" (fig. 4). Está claro cómo fue finalmente la reja, tal como la conocemos terminada. La desaparición de las cariátides o términos se había visto culminada con la de sus antagonistas alegorías de virtudes, eliminándose así gran parte del programa simbólico de la obra. Las grandes urnas pasaron a rematar los pedestales, y copas muy similares a las diseñadas en origen por Vergara "el viejo" las sustituyeron entre los pequeños obeliscos (fig. 5). Las columnas se habían simplificado, eliminando la poca decoración que portaban. El estípite también se eliminó finalmente. Los modelos de balaústre se mantuvieron (fig. 6). El platero toledano juzgó correcta, además, la factura técnica de la obra, con sus "secretos y clavaçones". Había visto estas interioridades muchas veces "en el año de setenta y dos y en el de noventa", por lo que le constaba lo bien hechas que estaban y firmes que resultarían. En total, apreció el valor de la reja en 11.500 ducados.

La tasación de Miguel Ruiz no se parece a esta primera de Merino porque está hecha al por menor y dando cuenta del valor de todas y cada una de las partes broncíneas de la obra y sus detalles técnicos (como gotas de soldaduras, ajustes, limados, cincelados). Confesó no 
tener conocimientos para valorar la obra de piedra. De entre todos los pormenores, destacaremos su valoración positiva de la desaparición de los festones de las columnas y la sustitución de las figuras de las virtudes por las urnas por constituir "mucha mexoría pa hermosear la dha obra y menos costa y mucho ahorro de dineros al colexio". Debido a lo detallado de la tasación de Ruiz, Merino realizó a continuación otra tasación pormenorizada sin cambiar su precio final.

Así que la obra definitiva quedaba muy resumida y simplificada, sin decoraciones superfluas, en un adusto dórico columnado de gran clasicidad a la romana y resonancias escurialenses -más en relación con el retablo broncíneo que con la arquitectura pétrea-, y con una lectura iconográfica que se reducía a los escudos (fíg. 7) (la inscripción de la obra se marginó finalmente a uno de los frentes de los pedestales historiados), a las urnas y a cada una de las caras o facetas de los paralelepípedos de las esquinas. Estos elementos reparten un epigrama latino y quince bajorrelieves, estos últimos ordenados por grupos. En cada uno de los cuatro pedestales podía verse una de las virtudes de Cisneros y varias escenas (figs. 8-12). El primero mostraba, además del epigrama $-\mathrm{y}$, como los otros, la virtud elegida-, dos de sus empresas religioso-culturales; el segundo, acontecimientos de su vida eclesiástica; el tercero, sus gestas político-mesiánicas; y el cuarto, sus fundaciones.

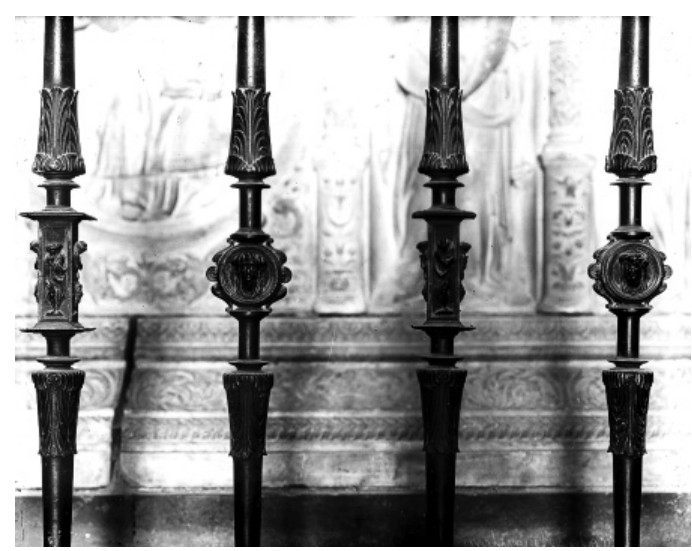

Fig. 6. Balaústres. Reja del sepulcro del Cardenal Cisneros. Archivo Moreno. IPHE, MC.

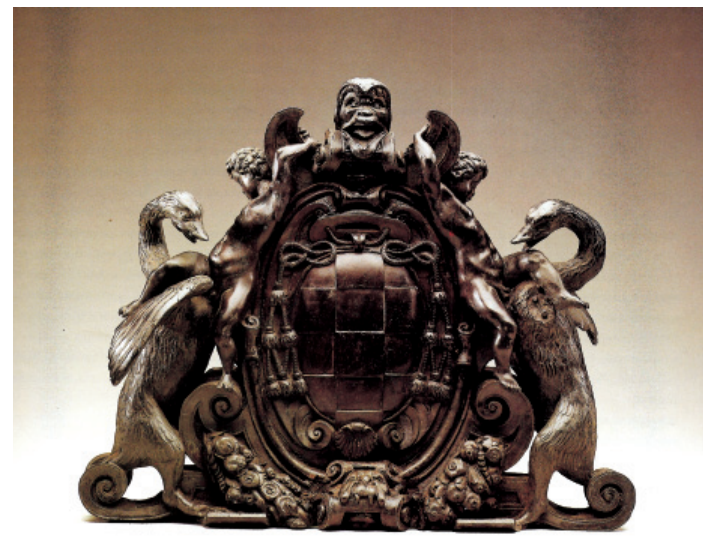

Fig. 7. Escudo. Reja del sepulcro del Cardenal Cisneros. Museo Arqueológico Nacional.

\section{El pleito y sus circunstancias}

El resto de documentos conservados en el legajo de la sección de Consejos del Archivo Histórico Nacional que estamos manejando, además de matizar ciertas cuestiones ya conocidas, nos da una completa visión de las circunstancias y desarrollo del pleito que se siguió ante el Consejo Real. A finales de agosto de 1590, el rector de Alcalá respondía a una solicitud de dinero del artífice, señalando que lo más oportuno era que la reja se asentase y tasase para poder así dar el dinero que correspondiese ${ }^{27}$. Después de terminar la obra, Nicolás de Vergara "el mozo" la

27 AHN, Consejos, Legajo 28281, folio 8 r. ${ }^{\circ}$ 

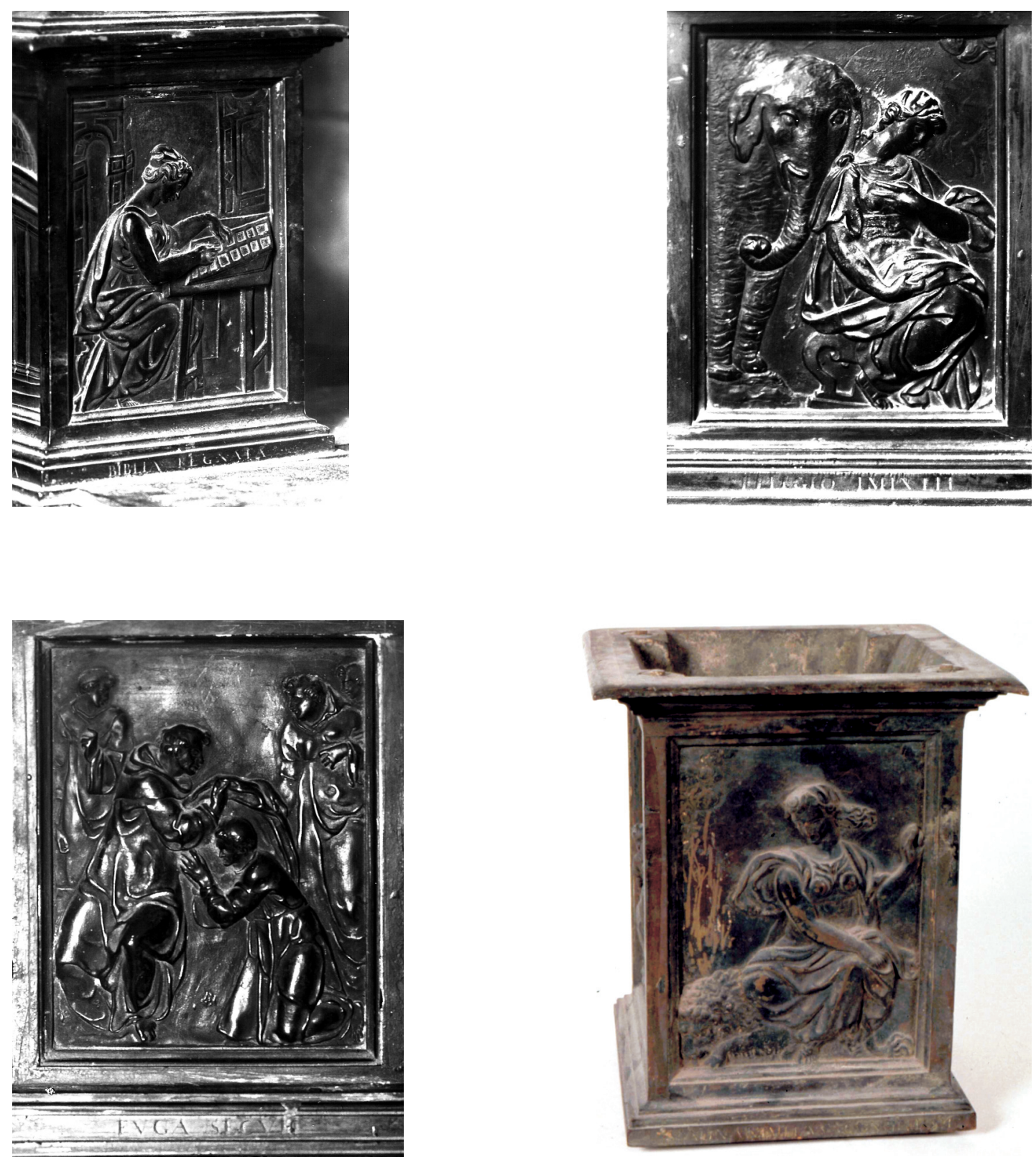

Reja del sepulcro del Cardenal Cisneros: Fig. 8. Biblia Regnata. Fig. 9. Religio Impvlit. Fig. 10. Fvga Secvli. Fig. 11. Magnanimitas Confirmavit. 

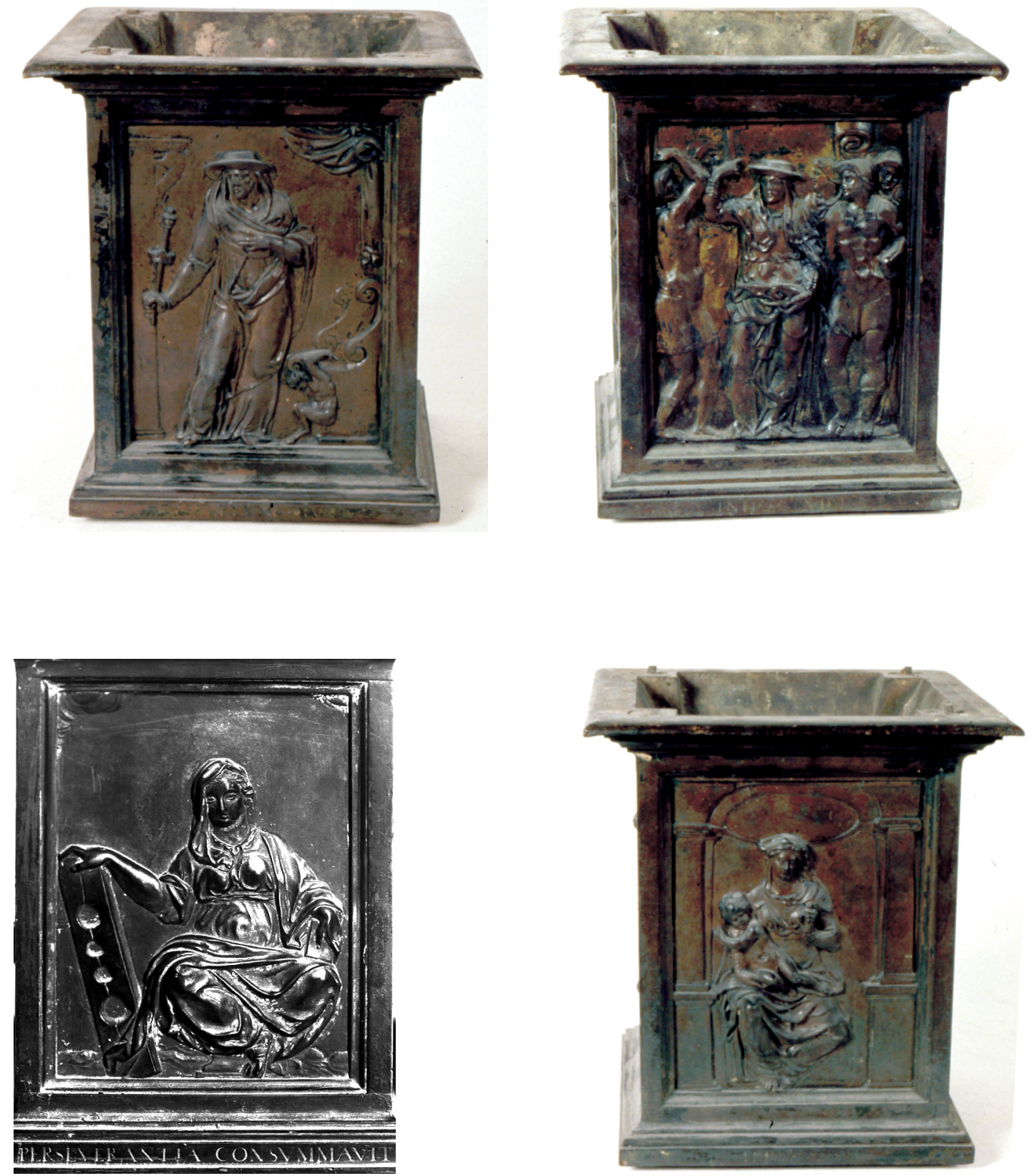

Reja del sepulcro del Cardenal Cisneros: Fig. 12. Respublica Recta. Fig. 13. In Hoc Vici. Fig. 14. Perseverantia Consummavit. Fig. 15. Illescensis. 

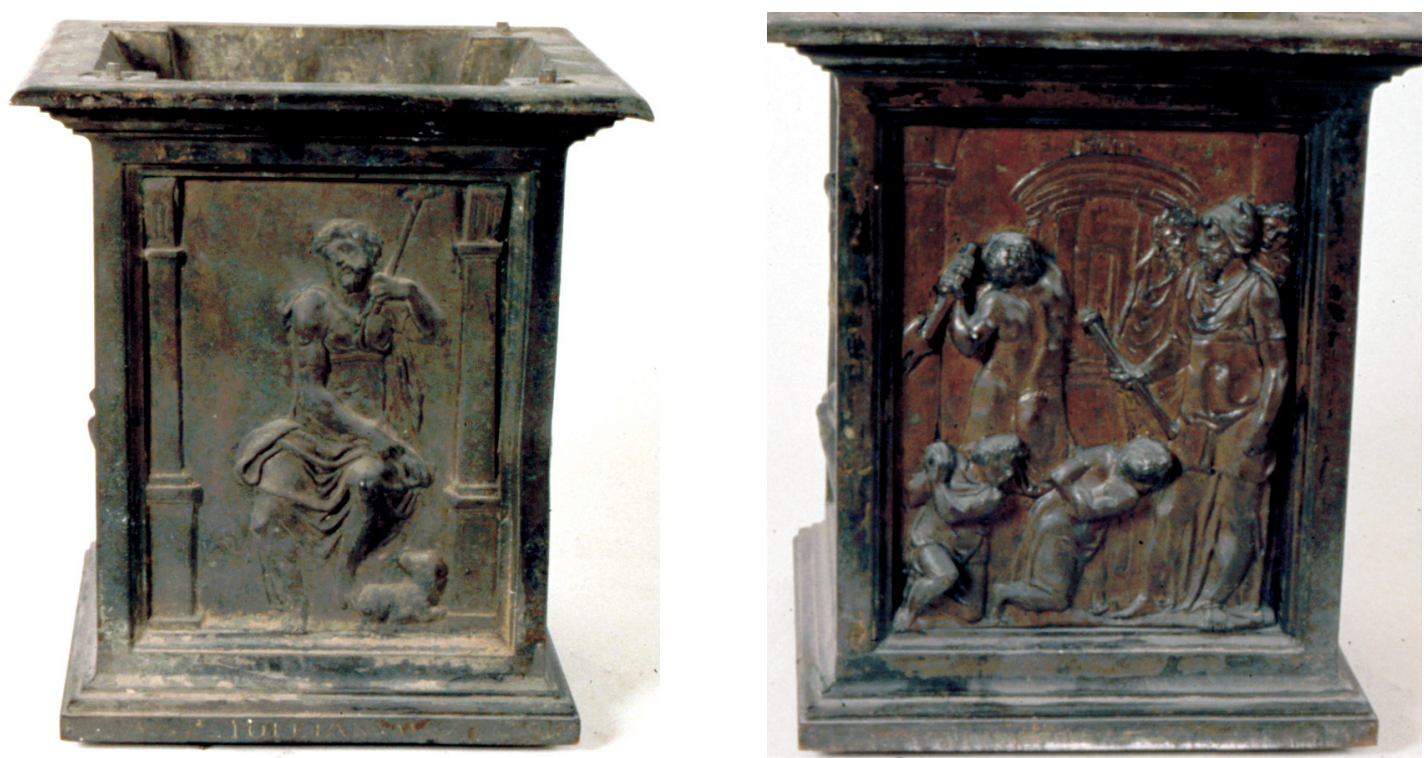

Reja del sepulcro del Cardenal Cisneros Museo Arqueológico Nacional: Fig. 16. Toletanus. Fig. 17. Theologia Aucta.

asentaba en la capilla de San Ildefonso. El mismo mes de junio de 1591 -día 7-, dos colegiales nombrados al efecto, procedían a tomar nota de un pesaje de la obra, lo que parece indicar el inicio de las suspicacias por parte de la Universidad ${ }^{28}$. De hecho, el día 15 siguiente, el colegial doctor Paredes hacía a un notario tomar testimonio de su opinión de que no se dejase asentar la reja a Vergara a no ser para tasarse y sin que ello supusiese que el Colegio la recibía y aceptaba. Esta actuación se realizaba a pesar de que Vergara ya había asentado la obra y debido a que solicitaba que se procediese a nombrar tasadores, iniciándose el procedimiento de tasación tal y como hemos visto arriba.

Como los tasadores de ambas partes no se concertaron en el precio, Vergara pidió formalmente y mediante notario, el 19 de junio, el nombramiento de tercer tasador neutral, según estaba previsto en las escrituras. En caso de que no se atendiese su petición, amenazaba con acudir al rey y al Consejo Real. Pero la capilla colegial contestó a Vergara que no había lugar a su petición, alegando defecto de forma e incumplimiento de plazos de ejecución. No tomaban ni aceptaban la obra, y si se dejó asentarla -añadían los colegiales- fue para que se tasase porque así lo especificaba la escritura de contrato. Además, los tasadores no habían tenido en cuenta el retraso en la ejecución, ignorando que los materiales y la mano de obra eran mucho menos costosos en la fecha de la contratación que en los años sucesivos hasta la conclusión de la pieza. Si el Colegio decidiera tomar la reja sería, entre otras cosas, en el caso de que los tasadores tuvieran en cuenta el desfase cronológico y sus consecuencias económicas para el Colegio. En tal caso, si aun así no se pusieran de acuerdo, se podría nombrar tercer tasador, pero el nombramiento la haría en solitario el rector, sin Vergara. Estas consideraciones se notificaron ante notario al artífice el 21 de junio del mismo año $1591^{29}$.

\footnotetext{
${ }^{28}$ Ibid., folio 78 r. $^{\circ}$ y v. ${ }^{\circ}$

${ }^{29}$ Petición de Vergara, repuesta del Colegio y sus notificaciones ante notario, en: Ibid., folios 2 r. $^{\text {- }}-3$ v. ${ }^{\circ}$
} 
Vergara dio un poder a un procurador para que llevase su causa a juicio, y éste presentó ante el Consejo Real un documento que porta registro de entrada en el alto tribunal de fecha del 27 de junio. Vergara exponía en él que los Colegiales le habían asegurado que asentando la reja le pagarían lo concertado. Una vez hecho lo que le pedían, se tasó la obra como estaba previsto y como los tasadores no se pusieron de acuerdo, pidió que se nombrase tercer tasador, de acuerdo con las escrituras. Pero los colegiales se negaban -como vemos-, por lo que solicitaba al alto tribunal que ordenase al rector colegial que hiciera lo que estaba obligado a hacer para que tasase la obra y se pagase al artífice. En caso contrario solicitaba que nombrase al tercer tasador el propio Consejo. Dada la contundencia de los argumentos de Vergara, el Consejo Real ordenó al Colegio, el 2 de julio, que nombrase tercero, o que se dejase a Vergara que se llevase la reja. Pero esto último no convenía a la parte denunciante, lo que su procurador comunicó al Consejo, a la vez que pedía copia de las escrituras concernientes al caso, la mayoría en poder del escribano del Colegio Universidad ${ }^{30}$. El tribunal respondía el 3 de julio que se diese una Real Provisión para que se sacasen las escrituras que se pedían, provisión fechada ese mismo día ${ }^{31}$. Cumpliendo lo ordenado, el 8 de julio el escribano de la Universidad sacó para la parte denunciante extractos de las partidas de cuentas sobre la reja que constaban en sus registros, entre 1566 y 1591, así como copias de las capillas del Colegio en las que constaba el mismo asunto, fechadas entre el 13 de noviembre de 1580 y el 9 de junio de $1591^{32}$.

Más adelante, el 19 de agosto, el Consejo Real ordenaba que el Colegio de Alcalá nombrase tercer tasador junto con Vergara, dando un plazo de diez días, tras el cual sería el Consejo el que lo nombrara, revocando, además, lo relativo a que el artífice se pudiese llevar la reja. La fecha del 23 de agosto tiene una Real Provisión en la que se ordenaba al Colegio el nombramiento del tercer tasador. Pero el Colegio no la obedeció, a pesar de que Vergara se ocupó de comunicársela ante notario (21 de septiembre), por lo que el procurador de "el mozo" procedió a solicitar que, pasado el plazo impuesto por el tribunal, éste nombrase al perito. El Consejo Real decidía nombrar, finalmente, a Pompeo Leoni, el 9 de noviembre ${ }^{33}$. El 29 de noviembre, el procurador del artífice de la reja interponía otra súplica en la que solicitaba confirmación de lo ya decidido por el Consejo ${ }^{34}$, en respuesta a las alegaciones de los representantes del Colegio. Entre esas alegaciones constaba una que decía que para contratar obras como la de la reja era necesaria la aprobación del visitador, amparándose en el artículo 25 de las constituciones del Colegio Universidad. El 9 de enero de 1592 una Real Provisión solicitaba copia de dicho artículo constitucional del Colegio, comunicándose el contenido de esta provisión ante notario a las dos partes. Se entregó la copia del artículo 25 al tribunal el 29 de abril de $1592^{35}$.

30 Súplica del procurador de Vergara y orden del tribunal en: Ibid., folios 9 r. ${ }^{\circ}-10$ v. ${ }^{o}$ Poder al procurador, en: Ibid., folio $1 \mathrm{r}^{\circ}$ En su alegación, la parte de Vergara señala sobre la reja: "Si agora se quitase no le seria de efecto para otra ninguna p.te ni se podría tassar bien estando quitada porque una de las mayores perfectiones que tiene es la hermosura que toda ella tiene y la correspondencia que haze al bulto y cama del Cardenal". Ibid., folio $10 \mathrm{v} .^{\circ}$

${ }^{31}$ La petición de copia de escrituras y la orden de dar la Real Provisión en: Ibid., folios 11 r. $^{\circ}-12$ v. ${ }^{\circ}$ La Real Provisión misma en: Ibid., folio $13 \mathrm{r}^{\circ}$

${ }^{32}$ Los extractos de las cuentas, en: Ibid., folios 61 r. $^{\circ}-66$ v. ${ }^{\circ}$ Copias de las capillas en: Ibid., folios 48 v. $.^{\circ}-60$ r. ${ }^{\circ} \mathrm{El}$ propio Vergara notificó al escribano, ante notario, la citada Real Provisión el 5 de julio: Ibid., folio 14 r. ${ }^{\circ}$

33 Orden del tribunal -10 de agosto- y plazo dado al Colegio en: Ibid., folio 12 v. ${ }^{\circ}$ Real Provisión del 23 de agosto en: Ibid., folio 69 r. ${ }^{\circ}$ y v. ${ }^{\circ}$ Comunicación de la Real Provisión ante notario: Ibid., folio 70 r. $^{\circ}$ Nombramiento de Leoni: Ibid., folio $67 \mathrm{r}^{\circ} \mathrm{y} \mathrm{v}^{\circ}{ }^{\circ}$

${ }^{34}$ Ibid., folio 74 r. $^{\circ}$ y v. ${ }^{\circ}$

${ }^{35}$ Real Provisión y documentos de notificación y copia de la constitución 25, en: Ibid., folios 84 r. ${ }^{\text {o- }} 87$ v. ${ }^{\circ}$ 
El 18 de abril entraba en el Consejo Real una súplica del procurador del Colegio que argumentaba contra Vergara que sus representados no aceptaban ni querían recibir la reja, que el asiento con Vergara "el viejo" se había hecho sin solicitarse permiso del Consejo Real por parte del Colegio y sin autorización del visitador como pedían las constituciones, por lo que si algo se debía reclamar era al rector y colegiales individuales que, contratando la obra, habían ido contra la normativa, no contra la institución. Además, consideraba que Vergara se había excedido enormemente en el valor de la reja sobre lo originalmente contratado, además de en tiempo, ya que de los ocho meses de plazo iniciales, se había demorado veinticinco años más. Se habían presupuestado 1.000 ducados y, dado el caso, se daría algo más por demasías, pero ahora se pedían 12.000 ( sic). Si el Colegio hubiera sabido que la obra tendría ese precio -decía-, no se habría embarcado en la empresa. Pero, además -razones que conocemos desde hace años-, se argumentaba que si se hubiese entregado la reja en el plazo inicialmente acordado, el montante de la tasación habría sido mucho menor. La subida de precios de materiales y salarios de veinticinco años había sido considerable y, dado que el retraso se achacaba a Vergara, se debía tener en cuenta a la hora de realizar la tasación, cosa que no había sucedido. Por último, el procurador del Colegio acusaba a los peritos de dolo, de manipulación y de estar complicados con Vergara. Por todo ello se pedía que Vergara se llevase su reja y que devolviese el dinero recibido a lo largo de todos esos años. El mismo 18 de abril, el Consejo Real confirmaba lo decidido anteriormente, desestimando toda esta serie de argumentaciones ${ }^{36}$.

El 23 de abril de 1592, una Real Provisión encargaba oficialmente a Pompeo Leoni que realizase la labor para la que se le había nombrado en tanto que tercer tasador de la reja del bronce del sepulcro de Cisneros. Se notificó a Leoni el 27 de julio de 1592, por petición de Vergara "el mozo". El 29 de julio un auto informa de la asistencia de Leoni a la villa complutense a realizar su peritaje del valor de la reja. Este documento va junto a las notificaciones a las partes y a sus peritos para que asistieran ${ }^{37}$. Leoni comunicó su parecer e informó de sus actuaciones al Consejo Real mediante un escrito fechado el 3 de agosto. Su tasación ascendió a 115.006 reales, alrededor de 10.400 ducados. El mismo día, el síndico del Colegio de Alcalá pedía copia de la tasación de Leoni $^{38}$.

El 17 de septiembre de 1592 el procurador del Colegio de Alcalá presentaba alegaciones similares a las anteriormente interpuestas, esta vez referidas a la tercera tasación, pues consideraba que Leoni no había tenido en cuenta detalles tan importantes como el desfase cronológico de encargo y entrega de la obra con las consecuencias económicas subsiguientes, o el precio real del latón y el bronce, además de que no consideraban estar los colegiales obligados a recibir la reja. Por último, se quejaba de que la tasación final superaba la aceptada por la parte del artífice en un principio, además de otros detalles de forma. En noviembre, el procurador del Colegio insistía en sus argumentos con otra súplica ${ }^{39}$. En abril de 1593 el procurador de Vergara solicitó al Consejo que nombrase un ejecutor para que acudiese a Alcalá y obligase al Colegio demandado a abonar de su dinero y bienes lo que se le debía al artífice toledano. El alto tribunal resolvió que se viese el pleito para sentencia ${ }^{40}$. Tras recibir otra súplica del procurador del denunciante,

\footnotetext{
${ }^{36}$ Súplica y auto en: Ibid., folios 72 r. $^{\circ}-73$ r. ${ }^{\circ}$

37 Provisión del 23 de abril de 1592 encargando a Leoni que hiciera la tasación: Ibid., folio 75 r. ${ }^{\circ}$ y v. ${ }^{\circ}$ Su notificación al italiano: Ibid., folio $76 \mathrm{r}^{\circ}{ }^{\circ}$ Auto con la actuación de Leoni y notificaciones: Ibid., folios 76 v. ${ }^{\circ}-77$ v. ${ }^{\circ}$

38 Tasación: Ibid., folios 79 r. ${ }^{\circ}-80$ r. ${ }^{\circ}$ Junto con el resto de la documentación constan las súplicas de Pompeo Leoni al Consejo real sobre las condiciones y el salario que se le debía abonar por su trabajo en la tasación de la reja: Ibid., folio $82 \mathrm{r}^{\circ} \mathrm{y} \mathrm{v}^{\circ}$ Petición de copia de la tasación: Ibid., folio $81 \mathrm{r} .^{\circ} \mathrm{y} \mathrm{v} .^{\circ}$

${ }^{39}$ Alegaciones del tasador del Colegio: (sept.) Ibid., folio $83 \mathrm{r}^{\circ} \mathrm{y} \mathrm{v}^{\circ}, \mathrm{y}$ (noviem.) folio $90 \mathrm{r}^{\circ} \mathrm{y} \mathrm{v}^{\circ}$

${ }^{40}$ Ibid., folios 88 r. ${ }^{\circ}$ y 89 v. ${ }^{\circ}$
} 
pues el Colegio quería alegar nuevamente, el 25 de mayo se confirmaba la resolución de que se viese para sentencia. Pero no fue necesario que el Consejo Real se manifestase finalmente en este asunto, pues el 5 de junio de 1593 ambas partes firmaban una escritura de concierto en la que se establecía el pago final por la obra y los plazos de su satisfacción, que se conocen sobradamente $^{41}$. El procurador del Colegio comunicó el concertado final del pleito al Consejo Real el 9 de julio de $1593^{42}$.

Fecha de recepción: 18-VII-2006

Fecha de aceptación: 4-XII-2006

${ }^{41}$ Súplica de la parte denunciante: Ibid., folio 92 r. $^{\circ}$ y v. ${ }^{\circ}$ Escritura de concierto: Ibid., folio 94 r. ${ }^{\circ}-97$ r. ${ }^{\circ}$ El Concierto o concordia, en cuaderno y con todos los pormenores, así como la confirmación del Consejo y la rúbrica de Felipe II, en AHN, Universidades, Carpeta 3, n. ${ }^{\circ} 10$ (antiguo Legajo 4, n. ${ }^{\circ}$ 26). Este documento aparece enteramente transcrito en Marchamalo, A. y Marchamalo, M., Ob. cit., pp. 179-192. Estos autores, sin embargo, citan la antigua signatura y no señalan la foliación correspondiente. Véase también Olaguer-Feliú, F. DE, Art. cit., p. 281. El primero en aludir a la concordia fue PonZ, A., Ob. cit., I, p. 292.

${ }^{42} \mathrm{AHN}$, Consejos, Legajo 28281, folio 93 r. $^{\circ} \mathrm{y} \mathrm{v}^{\circ}$ 